\title{
Photocatalytic activity of Al/Ni-doped TiO2 films synthesized by sol-gel method: Effect of sunlight photocatalysis on the catalysts properties
}

Elhachmi Guettaf Temam ( $\square$ elhachemi.guettaf@univ-biskra.dz )

Universite Mohamed Khider de Biskra https://orcid.org/0000-0001-6868-7484

\section{Faiçal Djani}

Universite Mohamed Khider de Biskra Faculte des Sciences Exactes et des Sciences de la Nature et de la Vie

\section{Saad Rahmane}

Universite Mohamed Khider de Biskra Faculte des Sciences Exactes et des Sciences de la Nature et de la Vie

Hachemi Ben Temam

Universite Mohamed Khider de Biskra Faculte des Sciences et de la Technologie

\section{Brahim Gasmi}

Universite Mohamed Khider de Biskra Faculte des Sciences et de la Technologie

\section{Research Article}

Keywords: Al, Ni doped TiO2, Thin films, Sol gel, Methylene blue, Photocatalysis, Sunlight

Posted Date: February 16th, 2021

DOI: https://doi.org/10.21203/rs.3.rs-211595/v1

License: (9) (1) This work is licensed under a Creative Commons Attribution 4.0 International License.

Read Full License 
Photocatalytic activity of $\mathrm{Al} / \mathrm{Ni}$-doped $\mathrm{TiO}_{2}$ films synthesized by sol-gel method: Effect of sunlight photocatalysis on the catalysts properties

\author{
Elhachmi Guettaf Temam ${ }^{*}$, Faiçal Djani ${ }^{2}$,Saad Rahmane ${ }^{1}$, Hachemi Ben Temam $^{1}$, Brahim Gasmi ${ }^{1}$ \\ ${ }^{1}$ Physics Laboratory of Thin Layers and Applications, Biskra University, BP 145 RP, Biskra 07000, Algeria \\ ${ }^{2}$ Molecular Chemistry Laboratory and Environment, University Mohamed Khider, 07000 Biskra, Algeria \\ * Corresponding author: elhachemi.guettaf@univ-biskra.dz (Elhachmi Guettaf Temam)
}

Tel: +213661273182

\begin{abstract}
Photocatalytic activity of semiconductors is affected by the nature of metal dopant. To study the effect of non-transition and transition metal on the physical and optical properties of $\mathrm{TiO}_{2}$ based photocatalysts; $\mathrm{Al}$ and Ni-doped $\mathrm{TiO}_{2}$ thin films respectively were prepared via a sol-gel dip-coating method. The effect of the photocatalysis process on the properties of $\mathrm{TiO}_{2}$ based thin films was investigated. The photocatalytic activity was calculated from methylene blue dye degradation under sunlight irradiation. XRD results show that un-doped $\mathrm{TiO} 2$ films were grown with anatase phase, whereas, the Ni and $\mathrm{Ni} / \mathrm{Al}^{-} \mathrm{doped} \mathrm{TiO}_{2}$ films show $\mathrm{Ti}_{4} \mathrm{O}_{7}$ single phase. The presence of $\mathrm{Al}$ preferred the rutile phase. No phases related to $\mathrm{NiO}$ or $\mathrm{Al}_{2} \mathrm{O}_{3}$ were detected. $\mathrm{Ni}-\mathrm{TiO} 2$ photocatalyst shows high photocatalytic activity ( 93\%) thanks to the high content of O and Ti, wide bandgap (3.35 eV), low crystal size $(6.87 \mathrm{~nm})$, high film thickness $(288 \mathrm{~nm})$, and high surface roughness $(44.5 \mathrm{~nm})$. After photocatalysis, all the films show a decrease in $\mathrm{O}$ content and thickness, whereas the indirect bandgap values were increased which suggesting the reuse with low photocatalytic activity.
\end{abstract}

\title{
Keywords:
}

Al, Ni doped $\mathrm{TiO}_{2}$; Thin films; Sol gel; Methylene blue; Photocatalysis; Sunlight.

\section{Introduction}

Titanium dioxide $\mathrm{TiO}_{2}$ is a versatile transition-metal oxide that has a large number of applications such as protective coatings [1-2], Photodetector [3], optical thin films [4-5], microelectronic devices [6], self-cleaning [7-9], and photocatalyst for the breakdown of organic contaminants in wastewaters [10-13]. All these applications are a traduction of their attractive properties such as high transmission in the visible region, wide band gap for anatase phase $(3.4 \mathrm{eV})$, and high photocatalytic activity under UV light [14]. 
As well known, there is two technologic ways for the illumination of organic substances from wastewater by the heterogeneous photocatalytic processes, i.e. suspended and fixed type. The suspended photocatalyst has more active surface sites than the fixed one due to its movement and nature of the material used (powder); however, its separation from treated solution is an issue [15]. The fixed photocatalyst has an advantage to mostly employ as thin films that are easy to use on an industrial scale at low cost.

In recent years, variety of researches have involved studying the photocatalytic properties of $\mathrm{TiO}_{2}$ thin films exposed under sunlight [16-18] and UV light radiations [19-21]. Wen et al. [22] studied the effect of doping TiO ${ }_{2}$ catalyst by I and F on the degradation rate of methylene blue and disclosed that $\mathrm{TiO}_{2}$ photocatalyst exhibited much higher activity under UV light than that under simulated sunlight. Yu et al. [23] reported that the photocatalytic activity of $\mathrm{TiO}_{2}$ thin film was remarkably enhanced by $\mathrm{Ni}$ doping at 0.5 at. $\%$ dopant concentration. The general mechanism of $\mathrm{TiO}_{2}$ semiconductor photocatalysis is described step by step in the literature [24, 25].

In this study, we purposed a cost-effective solution within the fields of wastewater treatment before putting it up. Aluminum and Nickel doped $\mathrm{TiO}_{2}$ photocatalyst thin films were synthesized on glass substrates by sol-gel dip-coating technique and then characterized. $\mathrm{Al}$ and $\mathrm{Ni}$ are chosen as non-transition and transition metal respectively, to study the effect of metal doped $\mathrm{TiO}_{2}$ thin films on the photodegradation rate of methylene blue dye under sunlight irradiation.

\section{Experimental details}

\subsection{Materials}

All chemicals were used as received from Sigma Aldrich without any purification. Double distilled water was used for all experiments. Sol-gel dip coating technique was used for the synthesis of $\mathrm{Al} / \mathrm{Ni} / \mathrm{TiO}_{2}$ thin films. Titanium (IV) isopropoxide $\left[\mathrm{Ti}\left(\mathrm{OCH}\left(\mathrm{CH}_{3}\right)_{2}\right)_{4}\right]$, Nickel (II) nitrate hexahydrate $\left[\mathrm{Ni}\left(\mathrm{NO}_{3}\right)_{2} \cdot 6 \mathrm{H}_{2} \mathrm{O}\right]$, and Aluminum nitrate nonahydrate $\left[\mathrm{Al}\left(\mathrm{NO}_{3}\right)_{3} .9 \mathrm{H}_{2} \mathrm{O}\right]$ were used as the precursor materials for $\mathrm{TiO}_{2}, \mathrm{Ni}$, and $\mathrm{Al}$ respectively. Water, isopropanol and ethanol were functioned as solvents. Glacial acetic acid was used as a chelating agent.

\subsection{Titanium dioxide-Ni-Al thin films synthesis}

The sol has been formed by dissolving TTIP in water and isopropanol (iPrOH) then stirred for 30 min. Later, Glacial acetic acid was added dropwise into the sol with vigorous stirring for $2 \mathrm{~h}$ at room temperature. The molar ratio of the components was optimized at $\mathrm{H}_{2} \mathrm{O}$ : $\mathrm{iPrOH}$ : TTIP: Glacial acetic acid = 2:25:1:1. The final solution is a transparent yellowish. To synthesis Al and $\mathrm{Ni}$ doped $\mathrm{TiO}_{2}$ thin films, Nickel (II) nitrate hexahydrate (Ni 3 wt. \%) and Aluminum nitrate nonahydrate (Al 3 wt. \%) were dissolved in $10 \mathrm{ml}$ ethanol for $60 \mathrm{~min}$ and then added to the previous solution respectively. 
Glass substrates were cleaned in acetone for 5 min to avoid any organic contamination and then washed with ethanol and water. The substrates were dipped in the prepared solutions for 30 seconds, and then withdrawn at a speed of $0.8 \mathrm{~mm} . \mathrm{s}^{-1}$ and dried at $100{ }^{\circ} \mathrm{C}$ for 5 min to evaporate organic solvents. The dip-coating procedure was repeated five times. All the $\mathrm{TiO}_{2}$ based thin films were calcined at $450^{\circ} \mathrm{C}$ for 3 hours.

\section{3. $\mathrm{Al} / \mathrm{Ni} / \mathrm{TiO}_{2}$ thin films caracterization}

The crystallographic structure of the films was evaluated by X-ray diffraction using a Bruker diffractometer (D8 Advance model) with CuKa radiation ( $\lambda=1.5406 \AA$ ), scanning from $20-80^{\circ}$ at a rate of $0.03^{\circ} \mathrm{s}^{-1}$. The $3 \mathrm{D}$ surface topography and the surface roughness of the films were analyzed by mechanical profilometer (Tencor P-7). The surface morphology of $\mathrm{Al} / \mathrm{Ni} / \mathrm{TiO}$ films was studied using (JEOL JSM 5800) scanning electron microscope (SEM) coupled with an energy dispersive X-ray analyzer (EDX) to study the chemical composition of the photocatalysts. The optical transmission spectra of the films were conducted with a UV-VIS JASCO V-770 spectrophotometer at a wavelength from 300-1500 nm.

\subsection{Photocatalytic caracterization}

The photocatalytic experiments by exploiting sunlight irradiation were conducted on the $15^{\text {th }}$ of December 2020 , under the conditions of the weather for that day (Biskra-Algeria). We intended to mention the date, as both the mean air temperature and relative humidity affect the solar radiation and therefore the photocatalytic efficiency of the films [26-30]. In addition, we aim for an in-depth study to compare the photocatalytic performance of $\mathrm{TiO}_{2}$ based thin films under sunlight irradiation every $15^{\text {th }}$ of each month.

In this study, Methylene blue (MB) dye has chosen as a model of wastewater contaminants. Photocatalytic degradation of MB solutions by $\mathrm{TiO}_{2}$ based thin films was investigated under sunlight irradiation. The photocatalyst samples $\left(20 \mathrm{~cm}^{2}\right)$ were dipped in $100 \mathrm{ml}$ of $\mathrm{MB}$ solution (2ppm), in a Pyrex beaker at an angle of $36^{\circ} \pm 1$ with tracking the direction of the sun manually during the experiments as an imitation of the solar panel system. Before the reaction, the photocatalyst was kept in the MB solution in the dark for $30 \mathrm{~min}$ to reach adsorption equilibrium, and then the irradiation tests were carried out from 8:30 am to 3:30 pm. During these experiments, the MB solution has stirred with a speed of $250 \mathrm{rpm}$.

\section{Results \& discussion}

\section{1. $\mathrm{TiO}_{2}$ based thin films properties}

Figure 1 shows the XRD patterns of $\mathrm{Al} / \mathrm{Ni} / \mathrm{TiO}_{2}$ thin films. The XRD pattern of pure $\mathrm{TiO}_{2}$ exhibits a tetragonal crystal structure with a single anatase phase (A) at the diffraction line $25.4^{\circ}$ (JCPDS: 00-002-0387); this result is similar to a previous study [31]. The $\mathrm{Ni}-\mathrm{TiO}_{2}$ film reveals that $\mathrm{Ni}$ doping $\mathrm{TiO}_{2}$ produced a change in the crystalline structure from anatase to anorthic structure of $\mathrm{Ti}_{4} \mathrm{O}_{7}$ phase [32] with diffraction line $31.7^{\circ}$ (JCPDS: 00-018-1402). The XRD result of $\mathrm{Al}-\mathrm{TiO}_{2}$ thin film shows two peaks at 38.4 
and $44.2^{\circ}$ corresponding to the $\mathrm{Ti}_{3} \mathrm{O}_{5}$ (Monoclinic, JCPDS: 00-011-0217) and rutile (Tetragonal, JCPDS: 00-003-1122) phase,

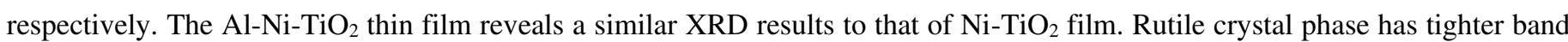
gap $(3.0 \mathrm{eV})$ than that of anatase phase $(3.4 \mathrm{eV})$ [33], therefore, it suggest low photocatalytic activity due to the recombinition of electrons from the conduction to the valence band (hole). Crystal size, porosity, and roughness of $\mathrm{TiO}_{2} \mathrm{material}$ are ones of important factors influencing its catalytic activity. Choi et al. [34] disclosed that small crystal size is of importance for high photocatalytic activity of $\mathrm{TiO}_{2}$ material. The primary crystal size was valued based on the effective crystal dimension $D$ computed using Scherrer equation which is given in the form

$$
D=0.9 \cdot \frac{\lambda}{B \cdot \cos \theta}
$$

Where 0.9 is the Scherrer constant, $\lambda$ is the wavelength of X-ray $(1.5406 \AA), B$ is the full wave half-maximum, and $\theta$ is the Bragg angle [35]. $D$ values were calculated for the most intense diffraction line (Table 1). The crystal size of $\mathrm{TiO}_{2}$ based thin films was around 6-9 $\mathrm{nm}$. Based on the literature $[36,37], \mathrm{Ni}_{-} \mathrm{TiO}_{2}$ catalyst promises high photocatalytic efficiency compared to other catalysts as it has small particle size $(6.87 \mathrm{~nm})$. Moreover, $\mathrm{Ni}$ and $\mathrm{Al}$ doping decrease the crystal size due to the incorporation of $\mathrm{Ni}^{2+}$ and $\mathrm{Al}^{3+}$ ions into cation sites of $\mathrm{TiO}_{2}$ lattice.

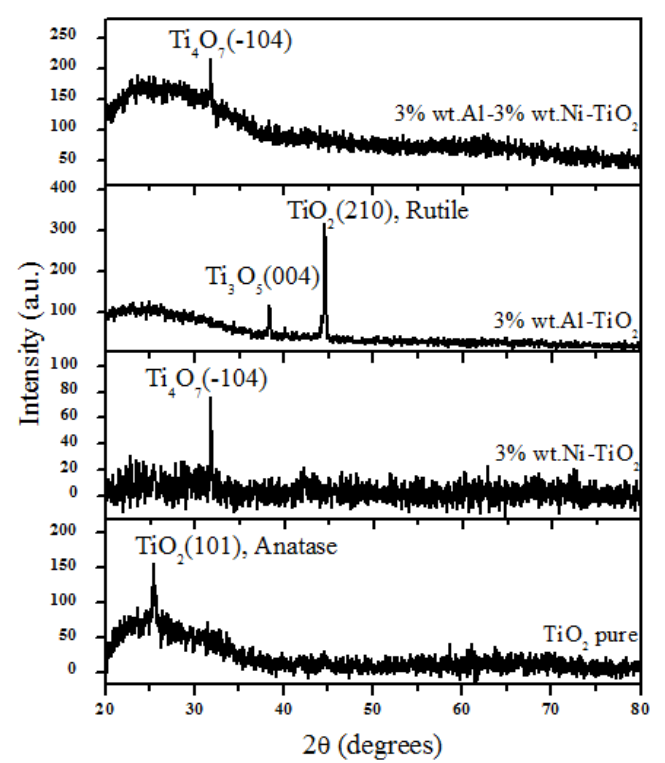

Fig. 1. XRD patterns of $\mathrm{TiO}_{2}$ based thin films. 

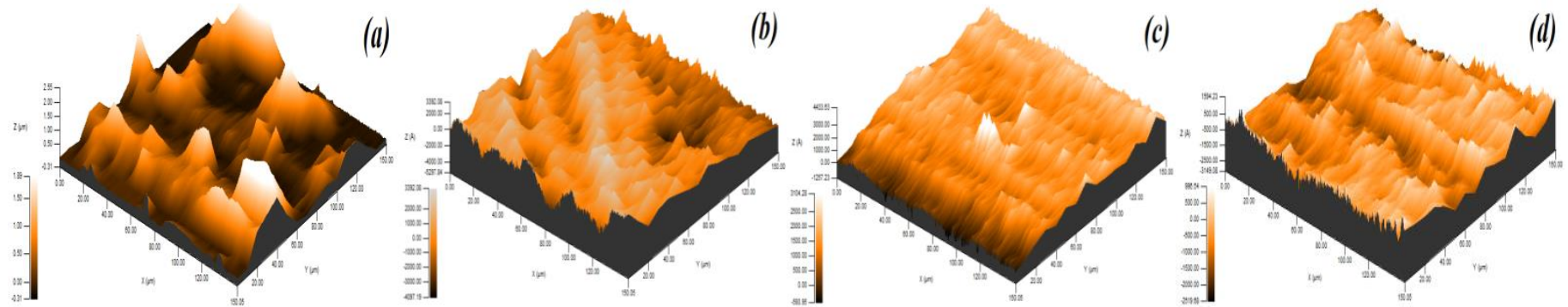

Fig. 2. 3D surface topography of $\mathrm{TiO}_{2}$ based thin films: (a) $\mathrm{TiO}_{2}$ pure, (b) 3 wt. $\% \mathrm{Ni}^{-\mathrm{TiO}_{2}}$, (c) 3 wt. $\% \mathrm{Al}-\mathrm{TiO}$, (d) 3 wt. $\% \mathrm{Ni}-3$ wt. $\% \mathrm{Al}-\mathrm{TiO}_{2}$.

The 3D surface topography of un-doped $\mathrm{TiO}_{2}$ and $\mathrm{Al} / \mathrm{Ni}$ doped $\mathrm{TiO}_{2}$ thin films is shown in Fig. 2. The root mean square $\left(\mathrm{R}_{\mathrm{q}}\right)$ surface roughness was calculated with the use of Apex analysis software (Table 1). The surface of $\mathrm{TiO}_{2}$ thin film is heterogeneous with a height equal to $1890 \mathrm{~nm}$. This surface is modified by the presence of Ni which makes the surface porous and flat with a certain difference in the density of pores dispersed randomly. Al doping $\mathrm{TiO}_{2}$ films makes the surface homogenous. The height of $\mathrm{Al} / \mathrm{Ni} / \mathrm{TiO}_{2}$ thin films is between $1.5-4.5 \mathrm{~nm} . \mathrm{R}_{\mathrm{q}}$ values are in the range of $30-45 \mathrm{~nm}(\mathrm{Table} 1) . \mathrm{Ni}^{-\mathrm{TiO}}{ }_{2}$ thin films suggest high photocatalytic efficiency for the discoloration of $\mathrm{MB}$ as it shows the high roughness value $44.5 \mathrm{~nm}$ [38]. Al-TiO 2 thin films have shown the lowest roughness $22.8 \mathrm{~nm}$ due to its homogenous surface.

Table. 1. Summary of analytical data

\begin{tabular}{|c|c|c|c|c|c|}
\hline \multirow[b]{3}{*}{ Parameters } & \multirow[b]{3}{*}{ Units } & \multicolumn{4}{|c|}{ Thin films } \\
\hline & & $\mathrm{TiO}_{2}$ & $\mathrm{Ni} / \mathrm{TiO}_{2}$ & $\mathrm{Al} / \mathrm{TiO}_{2}$ & $\mathrm{Al} / \mathrm{Ni} / \mathrm{TiO}_{2}$ \\
\hline & & & & & \\
\hline Crystallographic Phase & --- & (A) & $\mathrm{Ti}_{4} \mathrm{O}_{7}$ & (R) & $\mathrm{Ti}_{4} \mathrm{O}_{7}$ \\
\hline Crystal Size & $\mathrm{nm}$ & 8.38 & 6.87 & 7.58 & 6.97 \\
\hline Surface Roughness & $\mathrm{nm}$ & 30.7 & 44.5 & 22.8 & 31,7 \\
\hline Film Thickness & $\mathrm{nm}$ & 316 & 288 & 284 & 292 \\
\hline Transmission in Visible Range & $\%$ & $\sim 93$ & $\sim 88$ & $\sim 82$ & $\sim 85$ \\
\hline Optical Indirect Band Gap & $\mathrm{eV}$ & 3.41 & 3.35 & 3.32 & 3.26 \\
\hline Si Content & $\mathrm{wt} \%$ & 35.8 & 25.23 & 19.27 & 32.74 \\
\hline O Content & $\mathrm{wt} \%$ & 59.06 & 58.09 & 58.00 & 48.11 \\
\hline Ti Content & wt $\%$ & 11.14 & 15.63 & 20.88 & 16.50 \\
\hline Ni Content & wt $\%$ & -- & 1.06 & -- & 1.12 \\
\hline Al Content & wt $\%$ & -- & -- & 1.85 & 1.53 \\
\hline photocatalytic efficiency & $\%$ & $\sim 84$ & $\sim 93$ & $\sim 64$ & $\sim 86$ \\
\hline Rate constat & $h^{-1}$ & 0.224 & 0.428 & 0.159 & 0.320 \\
\hline
\end{tabular}



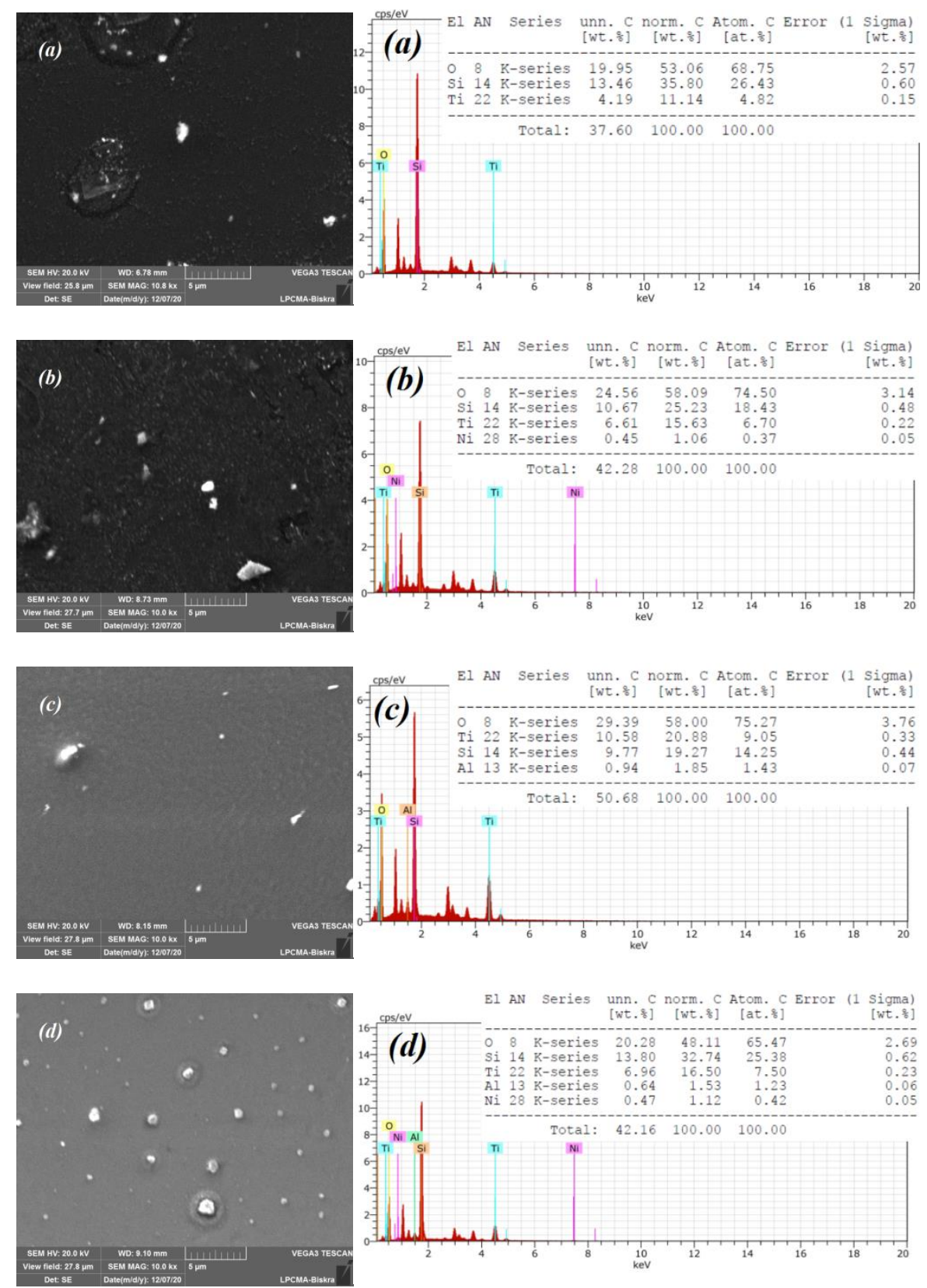

Fig. 3. SEM and EDX analyses of $\mathrm{TiO}_{2}$ based thin films: (a) $\mathrm{TiO}_{2}$ pure, (b) 3 wt. $\% \mathrm{Ni}-\mathrm{TiO}_{2}$, (c) 3 wt. $\% \mathrm{Al}-\mathrm{TiO}$, (d) 3 wt. $\% \mathrm{Ni}-3$ wt. $\% \mathrm{Al}-\mathrm{TiO}_{2}$.

SEM images of $\mathrm{TiO}_{2}$ based thin films show compact and uniform films as shown in Fig. 3. For Ni-TiO $\mathrm{T}_{2}$ thin films, it can be observed the presence of randomly distributed grains and pores which can increase the amount of MB adsorbed on these surfaces, and consequently, increasing the photocatalytic efficiency of the film. EDX analyses show a difference of the oxygen content in $\mathrm{TiO}_{2}$ based thin films. The increase in oxygen content in thin films increases its transmittance and thus giving high band gap energy $(\mathrm{Eg})$ value [33]. The $\mathrm{O}$ content in $\mathrm{TiO}_{2}$ thin films is in the range $48-59$ wt. $\%$ as shown in Fig. $3 . \mathrm{Ni}-\mathrm{TiO}{ }_{2}$ thin film shows the higher value of $\mathrm{O}$ content (58.09 wt. \%). $\mathrm{Al} / \mathrm{Ni}$ doped $\mathrm{TiO}_{2}$ thin films exhibits $\mathrm{Ni}$ and $\mathrm{Al}$ contents less than 2 wt. $\%$ (Table 1). The thickness ( $\mathrm{t}$ ) of $\mathrm{TiO}_{2}$ based thin films was estimated by the gravimetric method using the relation 


$$
t=\frac{M}{g \cdot A}
$$

Where $\mathrm{t}$ is the films thickness $(\mathrm{cm}), \mathrm{A}$ is the surface area of the films $\left(\mathrm{cm}^{2}\right), \mathrm{M}$ is the mass of the films $(\mathrm{g})$, and $\mathrm{g}$ is the density of

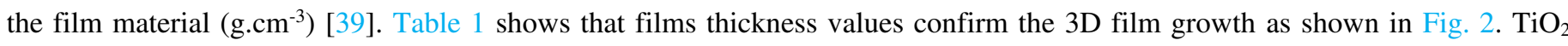
films with the best high $(1980 \mathrm{~nm})$ and much high crystal size $(8.38 \mathrm{~nm})$ is the thickest film. The doping of $\mathrm{TiO}_{2}$ films by $\mathrm{Ni}$ and Al reduce the thickness of the films to $288 \mathrm{~nm}$ and $284 \mathrm{~nm}$, respectively.
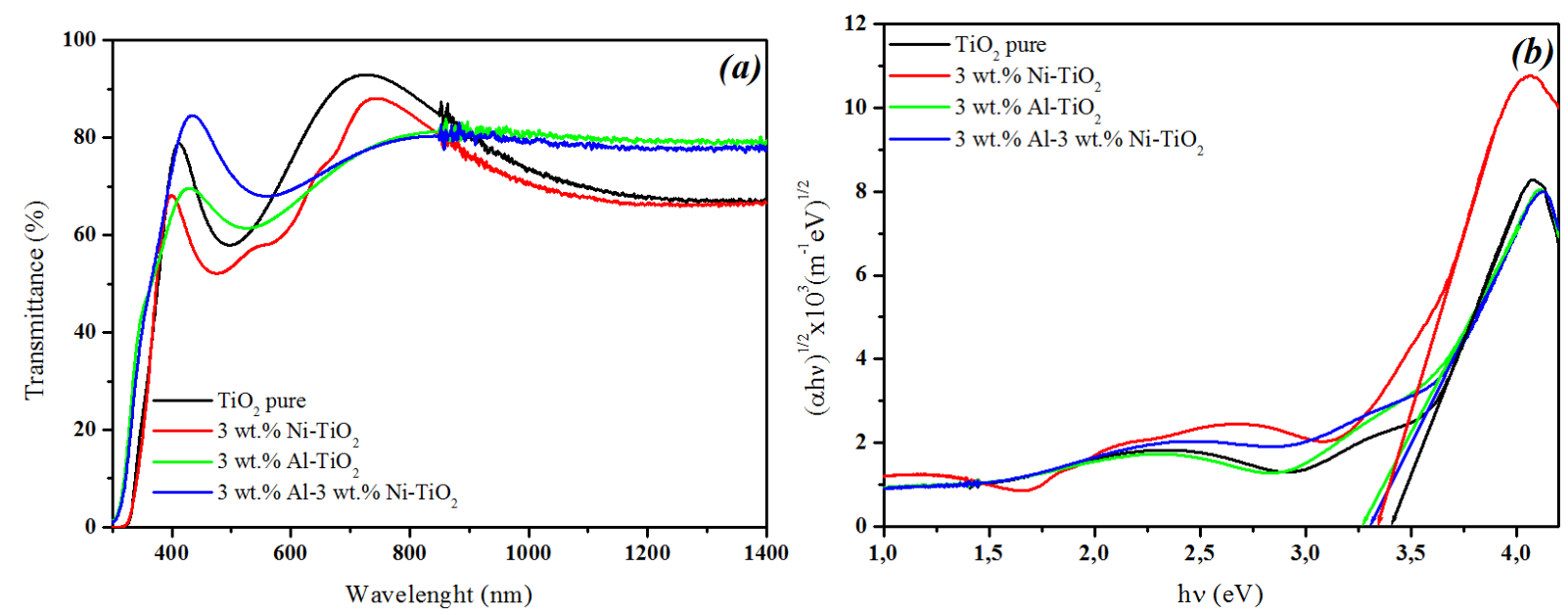

Fig. 4. (a) UV-VIS optical transmission spectra of $\mathrm{TiO}_{2}$ based thin films,

(b) Tauc plot for the optical band gap.

Figure 4 shows the optical transmission spectra of the films and Tauc plot for the optical band gap (Eg). The transmission spectra show high transparency in the visible region for all the $\mathrm{TiO}_{2}$ based thin films. These films have a transmittance values greater than 80\%. The highest transmittance value is for $\mathrm{TiO}_{2}$ pure with a high film thickness and oxygen content: $316 \mathrm{~nm}$ and $59.06 \mathrm{wt} . \%$, respectively. It is tempting to conclude that the average transmittance is a function of film thickness and oxygen content with a proportional relationship (Table1). The optical indirect band gap was estimated using Tauc and Menth method given by relation (eq. 3)

$$
\begin{gathered}
(\alpha h v)^{1 / 2}=C\left(h v-E_{g}\right) \\
\alpha=\frac{1}{t} \ln \left(\frac{T}{100}\right)
\end{gathered}
$$

Where $\alpha$ is the absorption coefficient $\left(\mathrm{m}^{-1}\right)$ (eq. 4$)$, which should be identified by the equation 4 , h is Planck's constant $\left(4.136^{*} 10^{-}\right.$ 15 eV.s), $v$ is Frequency of light $\left(\mathrm{s}^{-1}\right), \mathrm{C}$ is a Constant, Eg is Optical indirect band gap $(\mathrm{eV}), \mathrm{t}$ is the film thickness (m) and $\mathrm{T}$ is the optical transmittance (\%) [40]. The band gaps of the films slightly decreased with doping $\mathrm{TiO}_{2}$ thin films by $\mathrm{Ni}$ and $\mathrm{Al}$ ions owing to the change in crystallographic phase from anatase to $\mathrm{Ti}_{4} \mathrm{O}_{7}$ and rutile, respectively. In other hand, both degree of crystallinity [19], crystal size [17] and film thickness [39] are the of importance parameters controlling the film band gap value. Table 1 shows that the indirect band gap widens with increasing thickness [41]. The wide band gap $(3.41 \mathrm{eV})$ for $\mathrm{TiO}_{2}$ thin film agrees with high crystal size $(8.38 \mathrm{~nm})$ and thickness $(316 \mathrm{~nm})$. 


\subsection{Photocatalytic performance}

The photocatalytic performance of $\mathrm{TiO}_{2}$ based thin films was evaluated through the photodegradation of $\mathrm{MB}$ in an aqueous solution under sun irradiation. Fig. 5(a) shows that MB decomposes continuously throughout the entire irradiation time for Nidoped $\mathrm{TiO}_{2}$ thin films. The rate of degradation varies according to the hour of irradiation, since solar radiation is affected by temperature, humidity, wind speed, etc. The photocatalytic efficiency $(\gamma)$ is determined from the following equation [42]:

$$
\gamma \%=\frac{\left(C_{0}-C_{t}\right)}{C_{0}}
$$

Where $\mathrm{C}_{0}$ and $\mathrm{C}_{\mathrm{t}}$ are the concentrations of MB dye at times $\mathrm{t}=0$ and $\mathrm{t}$, respectively. The photodegradation of $\mathrm{MB}$ can be fitted by a pseudo-first-order reaction kinetic model [43, 44]:

$$
-\ln \left(\frac{C_{0}}{C_{t}}\right)=\kappa t
$$

Where $\mathrm{k}$ is the pseudo first-order rate constant $\left(\mathrm{h}^{-1}\right)$ and $\mathrm{t}$ is the irradiation time (hours). The degree of MB degradation was in the order $\mathrm{Ni} / \mathrm{TiO}_{2}>\mathrm{Al} / \mathrm{Ni} / \mathrm{TiO}_{2}>\mathrm{TiO}_{2}>\mathrm{Al} / \mathrm{TiO}_{2}$ as shown in Fig. 5. $\mathrm{Al} / \mathrm{TiO}_{2}$ (rutile phase) film shows lower photocatalytic efficiency ( $64 \%)$, than that of anatase $(\sim 84 \%) \mathrm{TiO}_{2}$ film (Table 1); it is well known that rutile phase has lower photocatalytic efficiency than anatase phase due to the low indirect band gap. Wang et al [45] studied the sonocatalytic degradation of methyl orange in the presence of nanometer anatase and rutile $\mathrm{TiO}_{2}$ powders. The compared sonocatalytic activities showed that the catalytic activity of nanometer anatase $\mathrm{TiO}_{2}$ powder is higher than that of nanometer rutile $\mathrm{TiO}_{2}$ powder. $\mathrm{Ni} / \mathrm{TiO}_{2}(\sim 93 \%)$, and $\mathrm{Al} / \mathrm{Ni} / \mathrm{TiO}{ }_{2}(\sim 86 \%)$ as sun catalysts show an effective degradation rate compared to that of anatase $\mathrm{TiO}_{2}$ catalyst due to the low crystal size, high roughness, and crystallographic phase $\left(\mathrm{Ti}_{4} \mathrm{O}_{7}\right)(\mathrm{Table} 1)$. Roughness enhancement increases surface area of the films [46], and consequently increases the quantity of adsorbed contaminant. Hence photodegradation predominates. In addition, the modification of $\mathrm{TiO}_{2}$ films surface by $\mathrm{Ni}^{2+}$ improves photocatalytic activity under sun light which can be attributed to the decreased recombination rate electron-hole pairs. As a transition metal, nickel metal is well known as it most often has remarkable catalytic properties and can form a wide variety of ionic species in a wide range of oxidation states which gives rise to variously colored complexes due to the different electronic transitions within the incomplete $3 \mathrm{~d}^{8}$ sub-shell. The doped metal plays an effective role in charge separation by capturing electrons. Begum et al. [47] discussed that $\mathrm{Ni}$ ions capture the electron that left a freer hole at the valence band which increases the holes concentration and leads to migrates to surface layer by withdrawing the electrons from the surface.

$\mathrm{K}$ values were determined by regression analysis of lines slopes in Fig. 5(c). Table 1 shows $\mathrm{K}$ values which increase with irradiation time for all $\mathrm{TiO}_{2}$ based photocatalysts. Figure 5(d) shows that the discoloration rate constant is largest with $\mathrm{Ni}$ doped $\mathrm{TiO}_{2}$ due to the low crystal size and high surface roughness. $\mathrm{Al}_{-}-\mathrm{TiO}_{2}$ (rutile) photocatalysts shows the smallest (k) value maybe owing to the high electron recombinition rate. Eva et al. [33] reported that as rutile adsorbs $\mathrm{OH}^{\bullet}$ more effectively than anatase, the 
amount of $\mathrm{OH}^{\bullet}$ generated on $\mathrm{TiO}_{2}$ and diffusing to the bulk solution would be lower in rutile crystallites. This result leads to conclude that
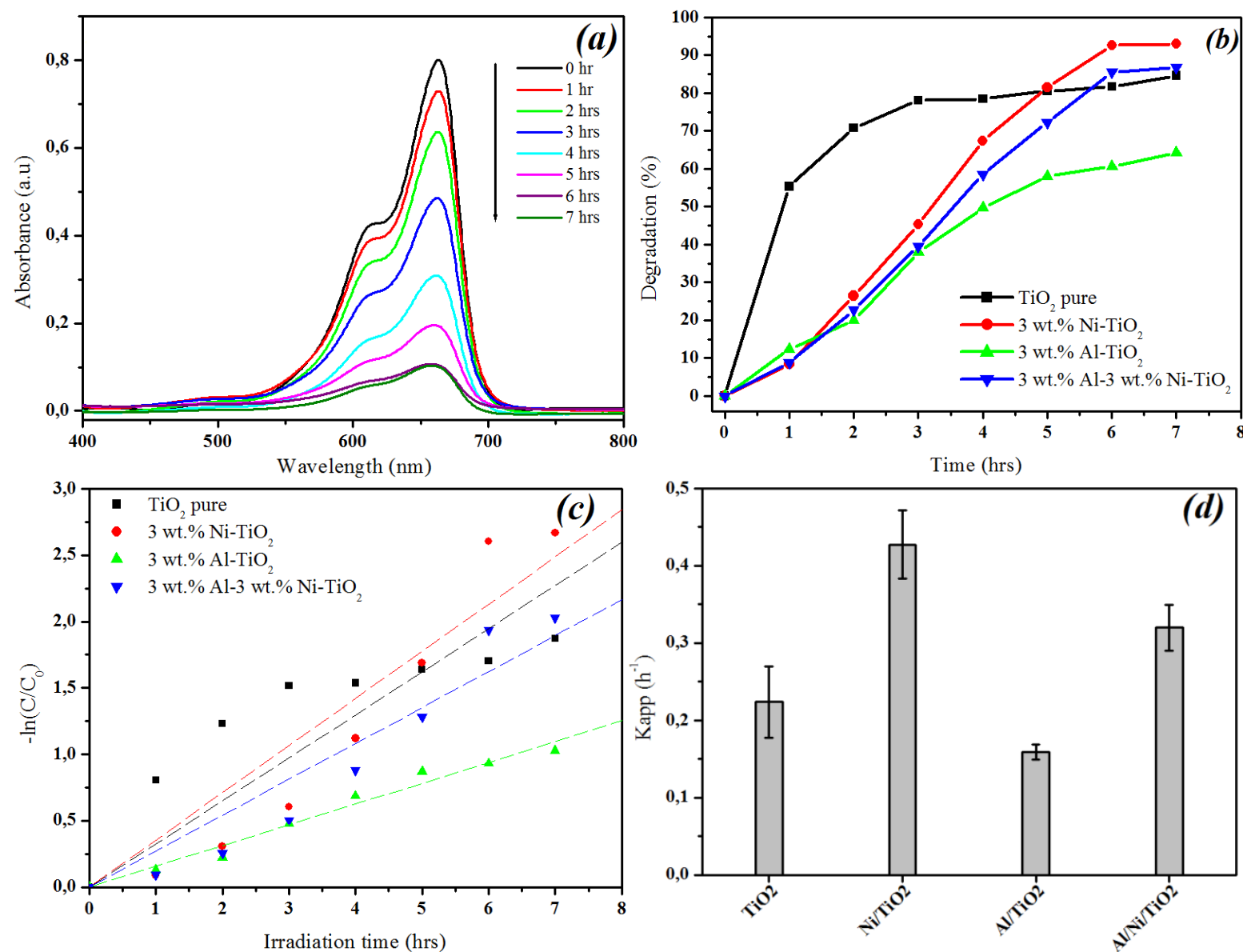

Fig. 5. (a) Variation of UV-vis spectra of MB during photodegradation over $\mathrm{Ni} / \mathrm{TiO}_{2}$ thin films; (b) Plot of photocatalytic efficiency versus the degradation time; (c) plot of $\ln \left(\mathrm{C} / \mathrm{C}_{0}\right)$ versus irradiation time for $\mathrm{TiO}_{2}$ based films; (d) rate constant $k$ of $\mathrm{MB}$ photodegradation.

the doping metal type on $\mathrm{TiO}_{2}$ photocatalysts is of most important effective parameter on the photodegradation of MB. As discussed in above, $\mathrm{Ni}$ doped $\mathrm{TiO}_{2}$ as transition metal increased the degree of photocatalysis under sunlight irradiation. In other hand, $\mathrm{Al}$ was chosen as non-transition metal (sub-shell: $3 \mathrm{p}^{1}$ ), which decreased the photocatalytic activity of $\mathrm{TiO}_{2}$ thin films.

\subsection{Effect of $\mathrm{MB}$ photodegradation process on the $\mathrm{TiO}_{2}$ based thin films properties}

Figure 6 shows surface morphology and EDX analyses of $\mathrm{TiO}_{2}$ based thin films after photodegradation experiments under sun light irradiation. It is clear to observe that the morphology of the samples is uniform and compact compared to that before photolysis experiments; maybe owing to the high photodegradation rates of MB dye that require high photocatalytic activity of the films which leads to erode of films outer coatings. These results suppose that the thickness and surface roughness of the films are decreased by the 

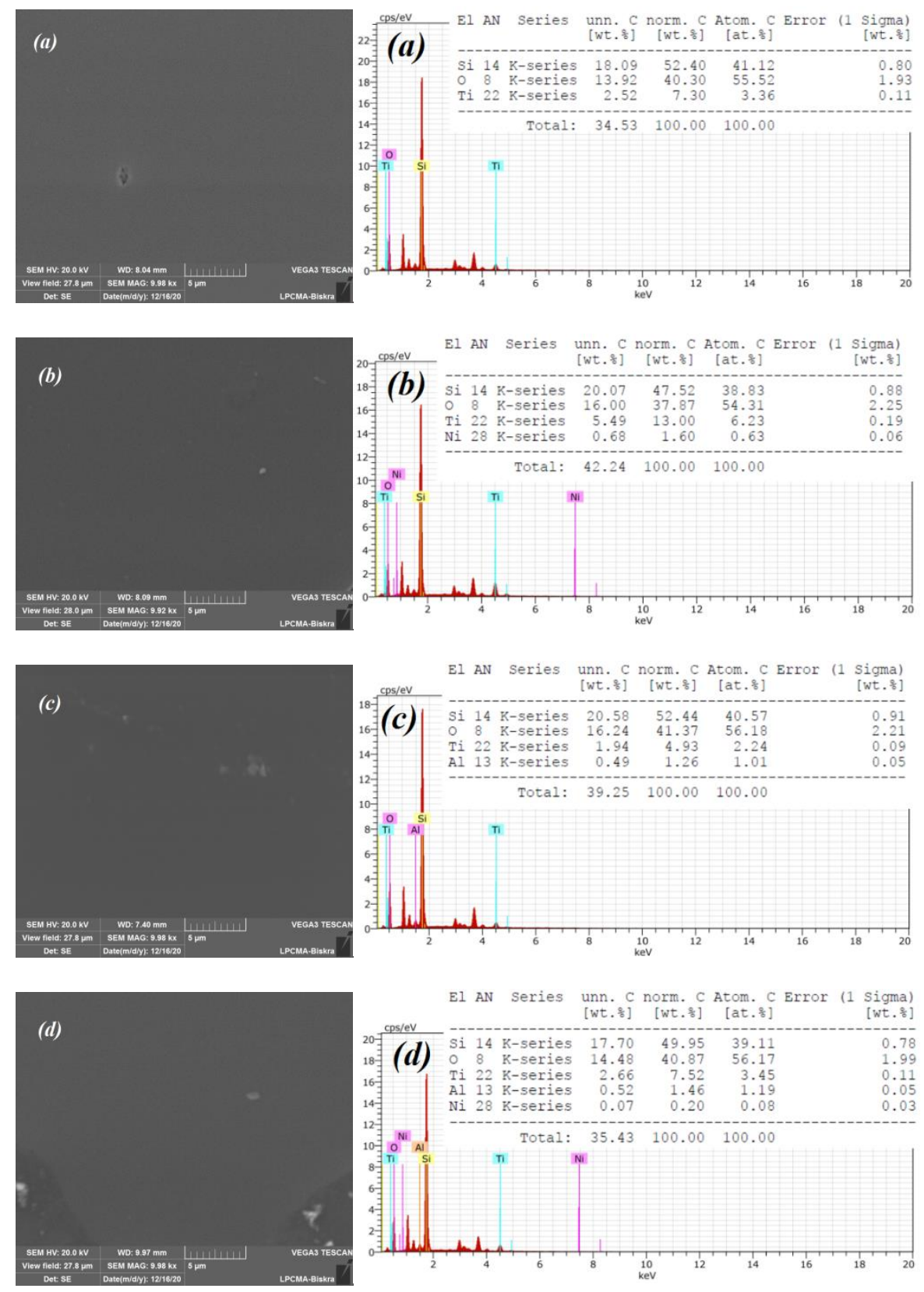

Fig. 6. SEM and EDX analyses of $\mathrm{TiO}_{2}$ based thin films after photodegradation process: (a) $\mathrm{TiO}_{2}$ pure, (b) 3 wt. $\% \mathrm{Ni}-\mathrm{TiO} 2$, (c) 3 wt. $\% \mathrm{Al}-\mathrm{TiO}_{2}$, (d) 3 wt. $\% \mathrm{Al}-3$ wt. $\% \mathrm{Ni}-\mathrm{TiO}_{2}$.

photolysis process. Hence, it is suggesting that the reuse of these samples for second cycle of photolysis gives low photodegradation rate than the first one. EDX results show that the content of Ti and $\mathrm{O}$ decreased by the photocatalysis application of these films as shown in Fig. 6(b). Hoffmann et al. [24] reported that unless oxygen is supplied on a continuous basis to a photocatalytic reactor, the rate of photocatalytic oxidation will decrease dramatically after depletion of the primary electron acceptor due to charge-carrier recombination. Overall, $\mathrm{Ti}$ and $\mathrm{O}$ contents are decreased owing to the photocatalytic oxidation of MB on bulk-phase $\mathrm{TiO}_{2}$. 


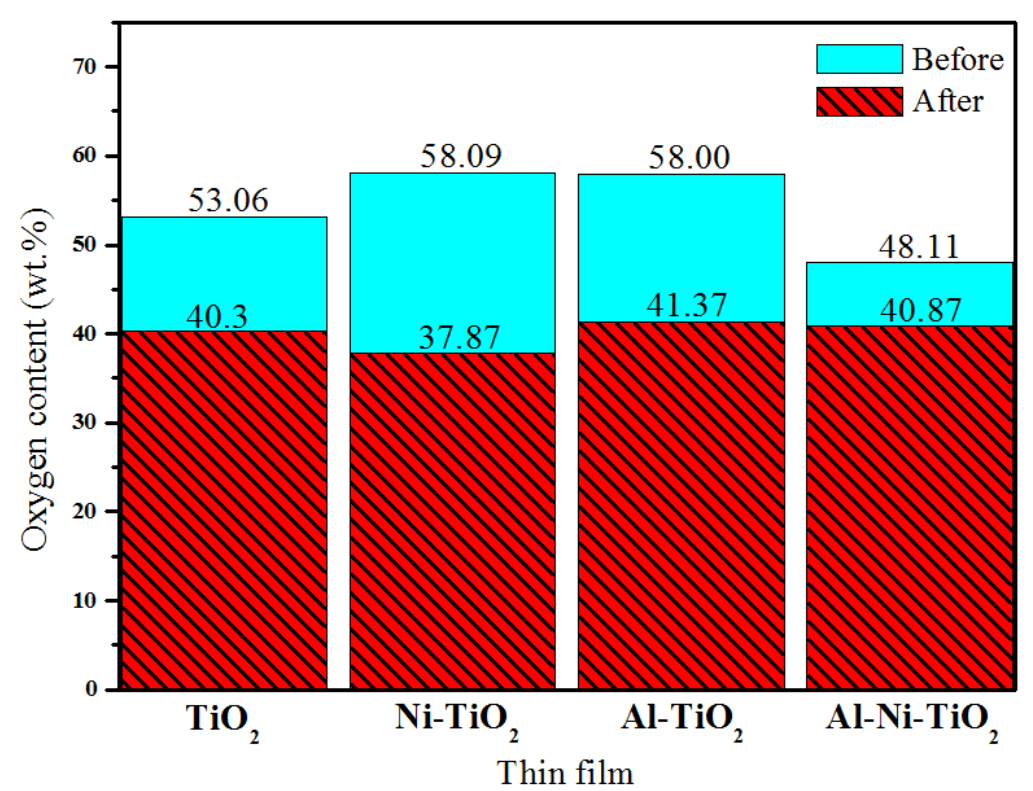

Fig. 7. Effect of photocatalysis process on oxygen content in the films.

Figure 7 shows the influence of photocatalysis process on oxygen content in the films. It is evident that the decrease in oxygen content is higher for $\mathrm{Ni}_{-} \mathrm{TiO}_{2}$ films due to the high photodegradation rate as the $\mathrm{O}$ is the electron acceptor and the principal oxidant. The decrease in $\mathrm{O}$ content leads to the decreasing optical transmission.

Figure 8 shows UV-Vis transmittance spectra of $\mathrm{TiO}_{2}$ based thin film samples and their indirect band gap after photolysis. Figure 8 (a) indicates the interference fringes which imply that the films are relatively flat after sun photocatalysis experiments. Overall, the optical transmission of the films decreased with decreased films thickness by photodegradation process (Table 2). Kim et al. [48] found that the optical transmission is not exponentially related to the film thickness. This result suggests that the transmission of the $\mathrm{TiO}_{2}$ based thin films is affected by other physical properties of the films. In this study, the transmission decreases is attributed to the decreased $\mathrm{O}$ content in the films by the sun photocatalysis process.
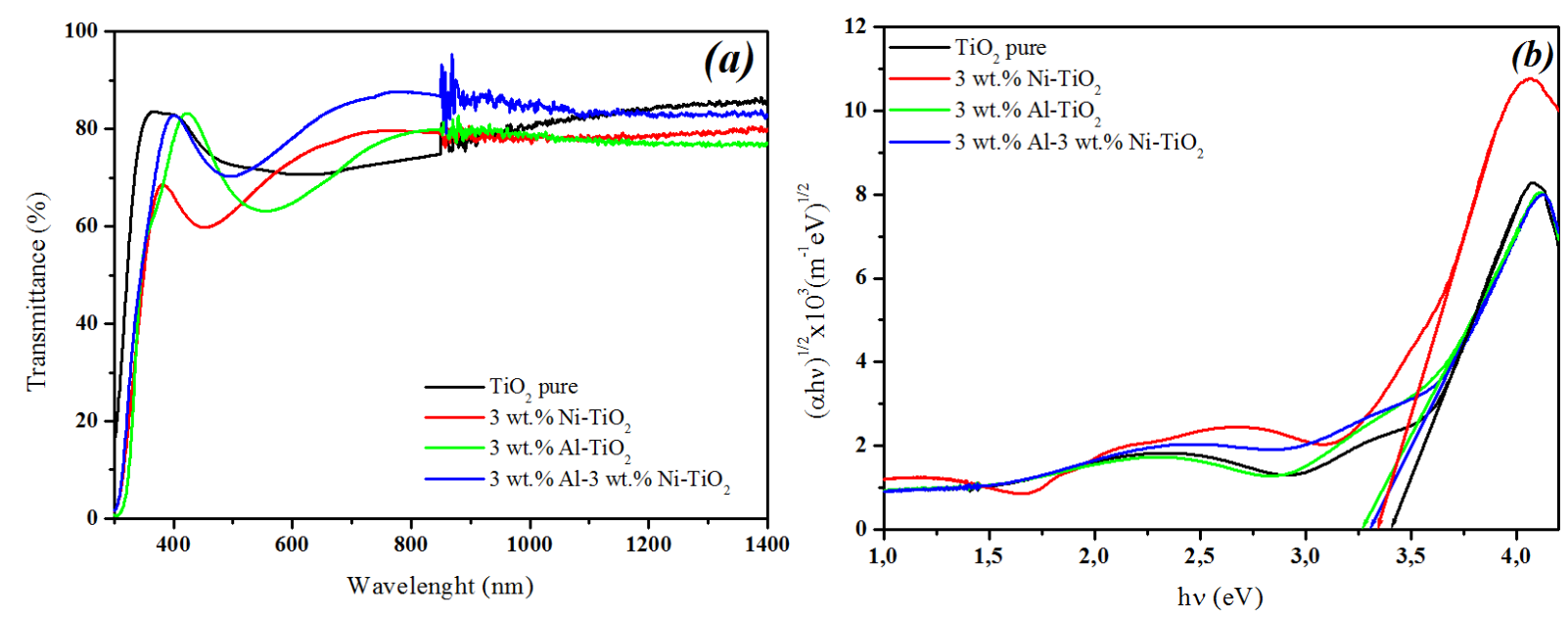

Fig. 8. (a) UV-VIS optical transmission spectra of $\mathrm{TiO}_{2}$ based thin films after photodegradation process, (b) Tauc plot for the optical band gap. 
Table. 2. Effect of photocatalysis process on the $\mathrm{TiO}_{2}$ based thin films properties

\begin{tabular}{|c|c|c|c|c|c|}
\hline \multirow[b]{3}{*}{ Parameters } & \multirow[b]{3}{*}{ Units } & \multicolumn{4}{|c|}{ Thin films } \\
\hline & & $\mathrm{TiO}_{2}$ & $\mathrm{Ni} / \mathrm{TiO}_{2}$ & $\mathrm{Al} / \mathrm{TiO}_{2}$ & $\mathrm{Al} / \mathrm{Ni} / \mathrm{TiO}_{2}$ \\
\hline & & & & & \\
\hline Film Thickness & $\mathrm{nm}$ & 223 & 252 & 281 & 265 \\
\hline Transmission in Visible Range & $\%$ & $\sim 83$ & $\sim 80$ & $\sim 82$ & $\sim 82$ \\
\hline Optical Indirect Band Gap & $\mathrm{eV}$ & 3.44 & 3.41 & 3.40 & 3.46 \\
\hline Si Content & $\mathrm{wt} \%$ & 52.40 & 47.52 & 52.44 & 49.95 \\
\hline O Content & $\mathrm{wt} \%$ & 40.30 & 37.87 & 41.37 & 40.87 \\
\hline Ti Content & $\mathrm{wt} \%$ & 7.30 & 13.00 & 4.93 & 7.52 \\
\hline Ni Content & $\mathrm{wt} \%$ & -- & 1.60 & -- & 0.20 \\
\hline $\mathrm{Al}$ Content & $\mathrm{wt} \%$ & -- & -- & 1.26 & 1.46 \\
\hline
\end{tabular}

Table 2 shows an increase in band gap with varying values according to the photocatalytic activities of the samples. This increase may lead to the low electron transfer kinetics from the valence band to the conduction band driving photo-oxidation of contaminants when using these samples for a second cycle. Trapping electron-hole of wide band gap semiconductors require high energy for photocatalysis than that of tighter one. This result suggests that using the samples for a second photocatalytic cycle may give less photodegradation rate than the first cycle. Bansode et al. [49] reused the Fe doped $\mathrm{TiO}_{2}$ thin films for three cycles as MB bleaching photocatalysts under UV light, and found that the nature of degradation remains unaltered.

\section{Conclusion}

This work focused on the effect of $\mathrm{Ni}$ and $\mathrm{Al}$ dopants as transition and non-transition metal respectively, on the photocatalytic performance of $\mathrm{TiO}_{2}$ thin films synthesized via sol-gel dip-coating technique. The photocatalytic performance of $\mathrm{TiO}_{2}$ based thin films were evaluated via the photodegradation of methylene blue under sunlight irradiation. Photocatalysis process show that grown phase, grain size, surface morphology and roughness, $\mathrm{O}$ content and indirect band gap are of importance parameters controlling the photocatalytic performance of $\mathrm{TiO}_{2}$ based thin films. 3 wt. $\%$ Ni- $\mathrm{TiO}_{2}$ photocatalysts show higher degradation rate $(\sim 93 \%)$ than the other deposits. The transition metal Ni dopant improves the physical and optical properties of $\mathrm{TiO}_{2}$ thin films. Thus the photodegradation of MB predominates. The use of 3 wt. \% Al as non-transition metal dopant impairs the photocatalytic activity of $\mathrm{TiO}_{2}$ thin films under sunlight irradiation.

\section{Declaration of interests}

The authors declare that they have no known competing financial interests or personal relationships that could have appeared to influence the work reported in this paper.

\section{References}

[1] AS Rad, Afshar A, Azadeh M (2020) Anti-reflection and self-cleaning meso porous $\mathrm{TiO}_{2}$ coatings as solar systems protective layer: Investigation of effect of porosity and roughness. Optical Materials 107:110027. 
[2] Ziadi I, Alves MM, Taryba M, El-Bassi L, Hassairi H, Bousselmi L, Montemor MF, Akrout H (2020) Microbiologically influenced corrosion mechanism of $304 \mathrm{~L}$ stainless steel in treated urban wastewater and protective effect of silane-TiO ${ }_{2}$ coating. Bioelectrochemistry 132:107413.

[3] Kara F, Kurban M, Coşkun B (2020) Evaluation of electronic transport and optical response of two-dimensional Fe-doped $\mathrm{TiO}_{2}$ thin films for photodetector applications. optik 210:164605.

[4] Zarhri Z, Cardos MÁA, Ziat Y, Hammi M, ElRhazouani O, Argüello JCC, Avellaneda DA (2020) Synthesis, structural and crystal size effect on the optical properties of sprayed $\mathrm{TiO}_{2}$ thin films: Experiment and DFT TB-mbj. Journal of Alloys and Compounds 819:153010.

[5] Salman SH, Shihab AA, Elttayef AHKh (2019) Studying The Effect of The Type of Substrate on The Structural ,Morphology and Optical Properties of $\mathrm{TiO}_{2}$ Thin Films Prepared by RF Magnetron sputtering. Energy Procedia 157:199-207.

[6] Green ML, Schenck PK, Chang KS, Ruglovsky J, Vaudin M (2009) "Higher-א" dielectrics for advanced silicon microelectronic devices: A combinatorial research study. Microelectronic Engineering 86:1662-1664.

[7] Adachi T, Latthe SS, Gosavi SW, Roy N, Suzuki N, Ikari H, Kato K, Katsumata KI, Nakata K, Furudate M, Inoue T, Kondo T, Yuasa M, Fujishima A, Terashima C (2018) Photocatalytic, superhydrophilic, self-cleaning $\mathrm{TiO}_{2}$ coating on cheap, light-weight, flexible polycarbonate substrates. Applied Surface Science 458:917-923.

[8] Navabpour P, Ostovarpour S, Hampshire J, Kelly P, Verran J, Cooke K (2014) The effect of process parameters on the structure, photocatalytic and self-cleaning properties of $\mathrm{TiO}_{2}$ and $\mathrm{Ag}-\mathrm{TiO}_{2}$ coatings deposited using reactive magnetron sputtering. Thin Solid Films 571:75-83.

[9] Peeters H, Keulemans M, Nuyts G, Vanmeert F, Li C, Minjauw M, Detavernier C, Bals S, Lenaerts S, Verbruggen SW (2020) Plasmonic gold-embedded $\mathrm{TiO}_{2}$ thin films as photocatalytic self-cleaning coatings. Applied Catalysis B: Environmental 267:118654.

[10] Anis SF, Hashaikeh R, Hilal N (2019) Functional materials in desalination: A review. Desalination 468:114077.

[11] Huo P, Yan Y, Li S, Li H, Huang W (2010) Floating photocatalysts of fly-ash cenospheres supported $\mathrm{AgCl}_{\mathrm{T}} \mathrm{TiO} \mathrm{f}_{2}$ films with enhanced Rhodamine B photodecomposition activity. Desalination 256:196-200.

[12] Bouanimba N, Zouaghi R, Laid N, Sehili T (2011) Factors influencing the photocatalytic decolorization of Bromophenol blue in aqueous solution with different types of $\mathrm{TiO}_{2}$ as photocatalysts. Desalination 275:224-230.

[13] Chen S, Cao G (2006) Study on the photocatalytic oxidation of $\mathrm{NO}_{2}$-ions using $\mathrm{TiO}_{2}$ beads as a photocatalyst. Desalination 194:127-134.

[14] Hamadanian M, Vanani AR, Behpour M, Esmaeily AS (2011) Synthesis and characterization of Fe, S-codoped TiO 2 nanoparticles: Application in degradation of organic water pollutants. Desalination 281:319-324.

[15] Horng RY, Huang C, Changb MC, Shao H, Shiaub BL, Hu YJ (2009) Application of $\mathrm{TiO}_{2}$ photocatalytic oxidation and nonwoven membrane filtration hybrid system for degradation of 4-chlorophenol. Desalination 245:169-182.

[16] Zahedi F, Behpour M, Ghoreishi SM, Khalilian H (2015) Photocatalytic degradation of paraquat herbicide in the presence $\mathrm{TiO}_{2}$ nanostructure thin films under visible and sun light irradiation using continuous flow photoreactor. Solar Energy 120:287295.

[17] Behpour M, Dehaghi RF, Mir N (2017) Considering photocatalytic activity of N/F/S-doped $\mathrm{TiO}_{2}$ thin films in degradation of textile waste under visible and sunlight irradiation. Solar Energy 158:636-643.

[18] Li J, Hou X, Sun T, Han J, Liu H, Li D (2019) Hydrophilic, antibacterial and photocatalytic properties of TiO 2 composite films modified by the methods of $\mathrm{N}^{+}$ion implantation and doping of CNTs under visible light irradiation. Surface and Coatings Technology 365:123-128. 
[19] Lin CP, Chen H, Nakaruk A, Koshy P, Sorrell CC (2013) Effect of Annealing Temperature on the Photocatalytic Activity of $\mathrm{TiO}_{2}$ Thin Films. Energy Procedia 34:627-636.

[20] Velasco-Hernández A, Esparza-Muñoz RA, de Moure-Flores FJ, Santos-Cruz J, Mayén-Hernández SA (2020) Synthesis and characterization of graphene oxide - $\mathrm{TiO}_{2}$ thin films by sol-gel for photocatalytic applications. Materials Science in Semiconductor Processing 114:105082.

[21] Rizzo L, Koch J, Belgiorno V, Anderson MA (2007) Removal of methylene blue in a photocatalytic reactor using polymethylmethacrylate supported $\mathrm{TiO}_{2}$ nanofilm. Desalination 211:1-9.

[22] Wen C, Zhu YJ, Kanbara T, Zhu HZ, Xiao CF (2009) Effects of I and F codoped $\mathrm{TiO}_{2}$ on the photocatalytic degradation of methylene blue. Desalination 249:621-625.

[23] Yu H, Li XJ, Zheng SJ, Xu W (2006) Photocatalytic activity of $\mathrm{TiO}_{2}$ thin film non-uniformly doped by Ni. Materials Chemistry and Physics 97: 59-63.

[24] Hoffmann MR, Martin ST, Choi W, Bahnemannt DW (1995) Environmental Applications of Semiconductor Photocatalysis. Chem. Rev. 95:69-96.

[25] Shapovalov VI (2010) Nanopowders and Films of Titanium Oxide for Photocatalysis:A Review. Glass Physics and Chemistry 36:121-157.

[26] Hashimoto Y, Ohashi Y, Nabeshima M, Shigeta Y, Kikegawa Y, Ihara T (2019) Sensitivity of electricity consumption to air temperature, air humidity and solar radiation at the city-block scale in Osaka, Japan. Sustainable Cities and Society 45:38-47.

[27] Rehman S, Mohandes M (2008) Artificial neural network estimation of global solar radiation using air temperature and relative humidity. Energy Policy 36:571-576.

[28] Behar O, Sbarbaro D, Marzo A, Moran L (2019) A simplified methodology to estimate solar irradiance and atmospheric turbidity from ambient temperature and relative humidity. Renewable and Sustainable Energy Reviews 116:109310.

[29] Ziarani NN, Haghighi AP (2019) Anticipating an efficient relative humidity in a room under direct solar radiation and equipped by radiant cooling panel systemAnticiper une humidité relative efficace dans une pièce exposée au rayonnement solaire direct et équipée d'un système de refroidissement par panneaux rayonnants. International Journal of Refrigeration 98 :98-108.

[30] Woolley J, Schiavon S, Bauman F, Raftery P (2019) Side-by-side laboratory comparison of radiant and all-air cooling: How natural ventilation cooling and heat gain characteristics impact space heat extraction rates and daily thermal energy use. Energy and Buildings 200:68-85.

[31] Magalhães F, Moura FCC, Lago RM (2011) $\mathrm{TiO}_{2}$ /LDPE composites: A new floating photocatalyst for solar degradation of organic contaminants. Desalination 276:266-271.

[32] Tsumura T, Hattori Y, Kaneko K, Hirose Y, Inagaki M, Toyoda M (2004) Formation of the $\mathrm{Ti}_{4} 0_{7}$ phase through interaction between coated carbon and $\mathrm{TiO}_{2}$. Desalination 169:269-275.

[33] Relinque EJ, Castellote M ( 2018) Hydroxyl radical and free and shallowly trapped electron generation and electron/hole recombination rates in $\mathrm{TiO}_{2}$ photocatalysis using different combinations of anatase and rutile. Applied Catalysis A: General $565: 20-25$

[34] Choi H, Stathatos E, Dionysiou DD (2007) Photocatalytic $\mathrm{TiO}_{2}$ films and membranes for the development of efficient wastewater treatment and reuse systems. Desalination 202:199-206.

[35] Kitazawa S, Choi Y, Yamamoto S, Yamaki T (2006) Rutile and anatase mixed crystal $\mathrm{TiO}_{2}$ thin films prepared by pulsed laser deposition. Thin Solid Films 515:1901-1904.

[36] Eufinger K, Poelman D, Poelman H, De Gryse R, Marin GB (2007) Effect of microstructure and crystallinity on the photocatalytic activity of $\mathrm{TiO}_{2}$ thin films deposited by dc magnetron sputtering. Journal of Physics D: Applied Physics 40:52325238. 
[37] Komaraiah D, Radha E, Sivakumar J, Ramana Reddy MV, Sayanna R (2019) Structural, optical properties and photocatalytic activity of $\mathrm{Fe}^{3+}$ doped $\mathrm{TiO}_{2}$ thin films deposited by sol-gel spin coating. Surfaces and Interfaces 17 (2019) 100368.

[38] Malengreaux CM, Léonard GML, Pirard SL, Cimieri I, Lambert SD, Bartlett JR, Heinrichs B (2014) How to modify the photocatalytic activity of $\mathrm{TiO}_{2}$ thin films through their roughness by using additives. A relation between kinetics, morphology and synthesis. Chemical Engineering Journal 243: 537-548.

[39] Abdelkrim A, Rahmane S, Abdelouahab O, Hafida A, Nabila K (2016) Optoelectronic properties of $\mathrm{SnO}_{2}$ thin films sprayed at different deposition times. Chinese Phys. B 25:046801.

[40] Tauc J, Menth A (1972) States in the gap. J. Non-Cryst Solids 8-10:569-585.

[41] Rahmane S, Aida MS, Djouadi MA, Barreau N (2015) Effects of Thickness Variation on Properties of ZnO:Al Thin Films Grown by RF Magnetron Sputtering Deposition. Superlattices and Microstructures 79:148-155.

[42] Zhang D, Zhang M, Chen S, Liang Q, Sheng N, Han Z, Cai Y, Wang H (2021) Scalable, self-cleaning and self-floating bilayered bacterial cellulose biofoam for efficient solar evaporator with photocatalytic purification. Desalination 500:114899.

[43] Zayani G, Bousselmi L, Mhenni F, Ghrabi A (2009) Solar photocatalytic degradation of commercial textile azo dyes: Performance of pilot plant scale thin film fixed-bed reactor. Desalination 246:344-352.

[44] Mahvi AH, Ghanbarian M, Nasseri S, Khairi A (2009) Mineralization and discoloration of textile wastewater by $\mathrm{TiO}_{2}$ nanoparticles. Desalination 239:309-316.

[45] Wang J, Ma T, Zhang Z, Zhang X, Jiang Y, Pan Z, Wen F, Kang P, Zhang P (2006) Investigation on the sonocatalytic degradation of methyl orange in the presence of nanometer anatase and rutile $\mathrm{TiO}_{2}$ powders and comparison of their sonocatalytic activities. Desalination 195:294-305.

[46] Bharti B, Kumar S, Kumar R (2016) Superhydrophilic $\mathrm{TiO}_{2}$ thin film by nanometer scale surface roughness and dangling bonds. Applied Surface Science 364:51-60.

[47] Begum NS, Ahmed HMF, Gunashekar KR (2008) Effects of Ni doping on photocatalytic activity of $\mathrm{TiO}_{2}$ thin films prepared by liquid phase deposition technique. Bull. Mater. Sci. 31:747-751.

[48] Kim H, Gilmore CM (1999) Electrical, optical, and structural properties of indium-tin-oxide thin films for organic lightemitting devices. J. Appl. Phys. 86:6451-6461.

[49] Bansode AS, More S, Bhoraskar SV, Mathe VL (2015) Reusable thin film photocatalyst of Fe-doped TiO 2 deposited by ECR plasma, surface and interface analysis 47:22-29. 
Figures

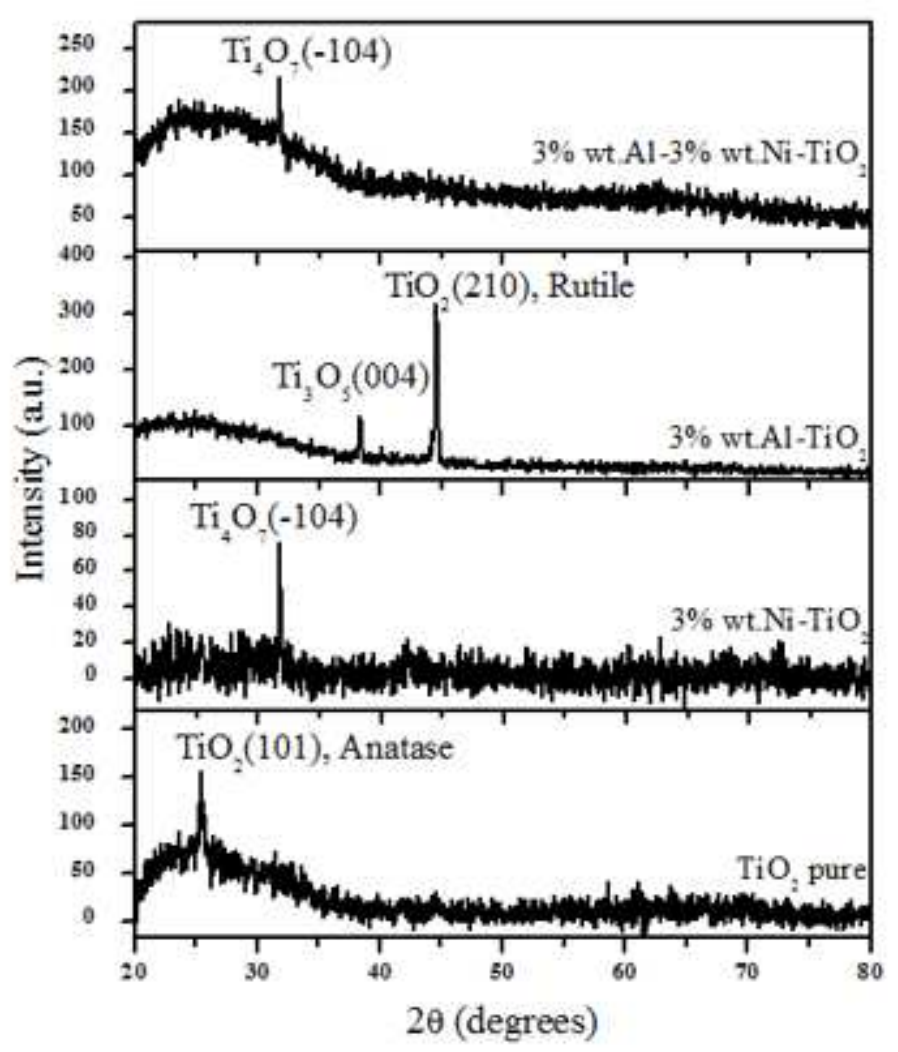

Figure 1

XRD patterns of TiO2 based thin films.
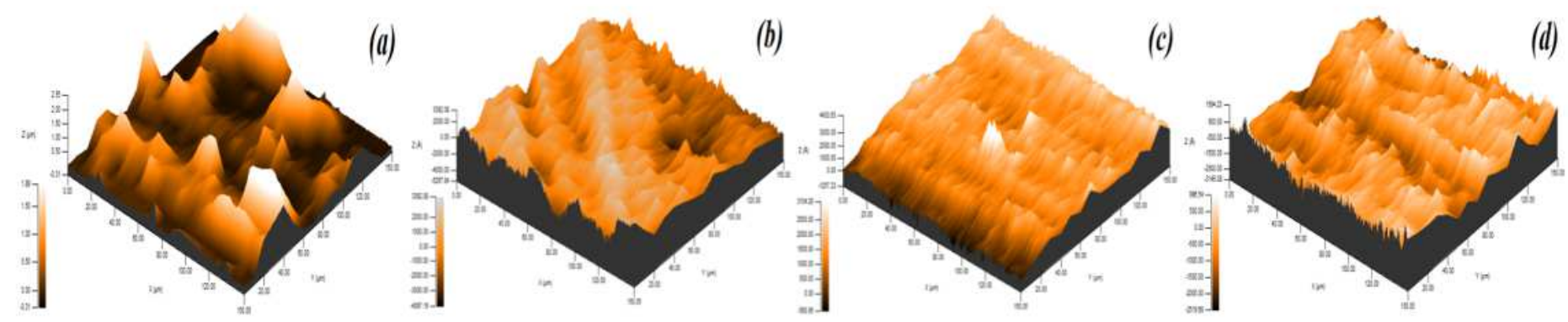

Figure 2

3D surface topography of TiO2 based thin films: (a) TiO2 pure, (b) 3 wt. \%Ni-TiO2, (c) 3 wt. \%Al-TiO2, (d) 3 wt. \%Ni-3 wt. \%Al-TiO2. 

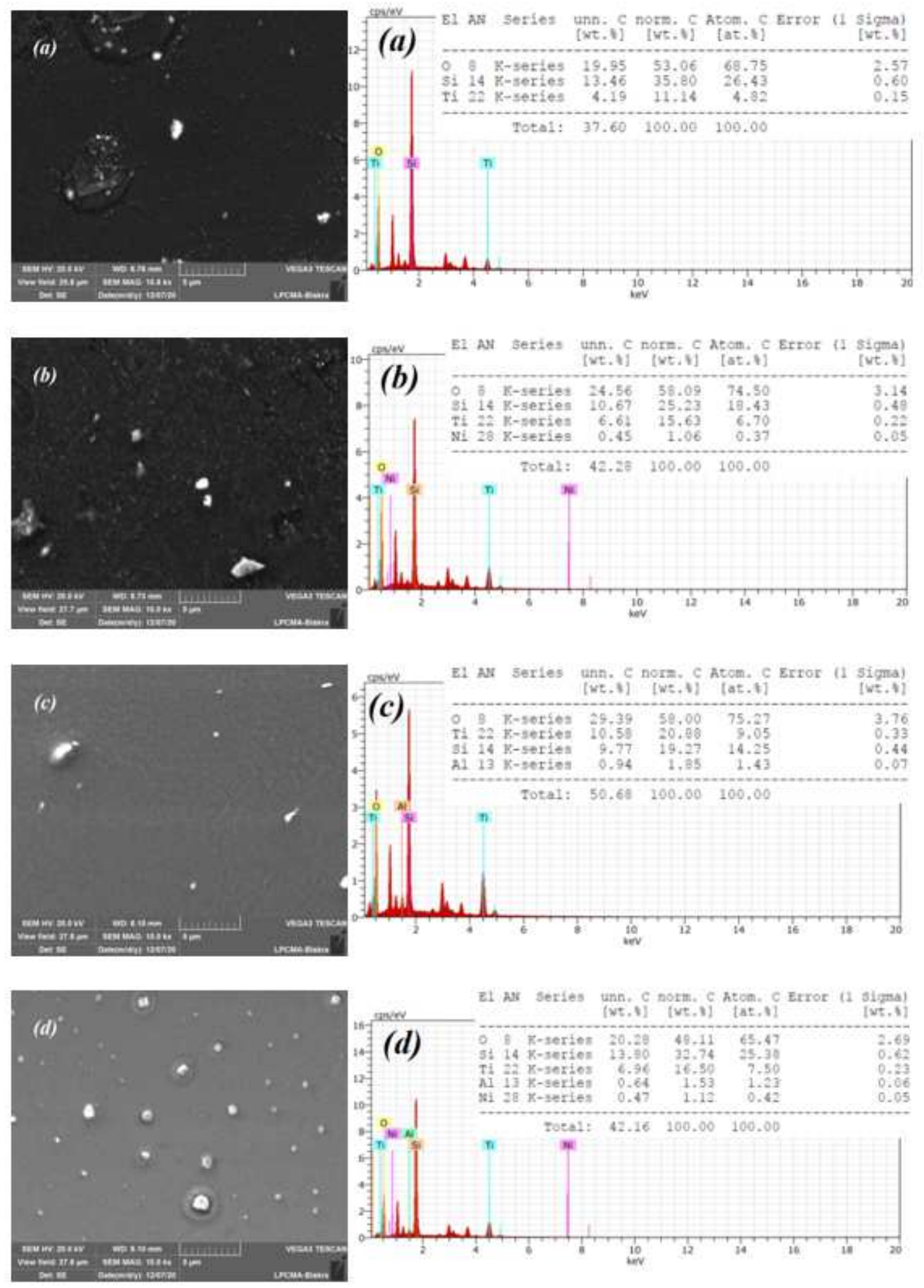

\section{Figure 3}

SEM and EDX analyses of TiO2 based thin films: (a) TiO2 pure, (b) 3 wt. \%Ni-TiO2, (c) 3 wt. \%Al-TiO2, (d) 3 wt. \%Ni-3 wt. \%Al-TiO2. 

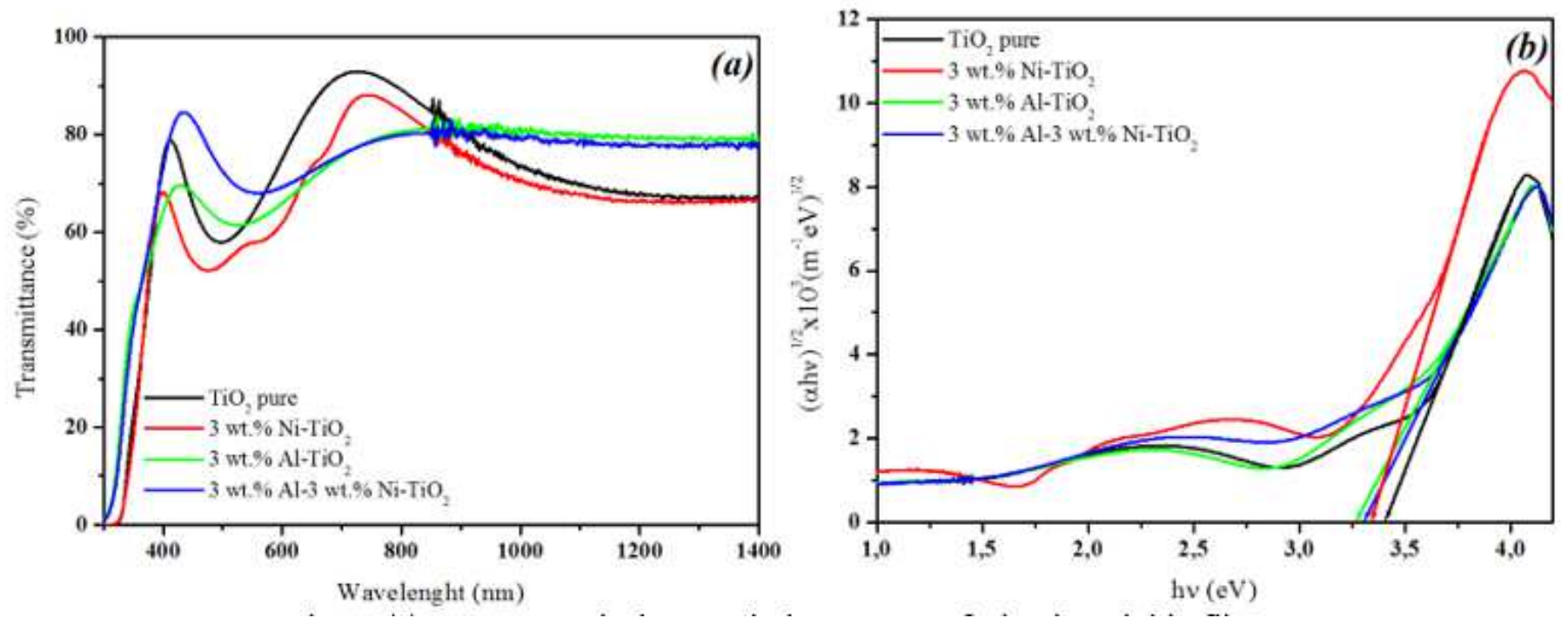

Figure 4

(a) UV-VIS optical transmission spectra of TiO2 based thin films, (b) Tauc plot for the optical band gap.
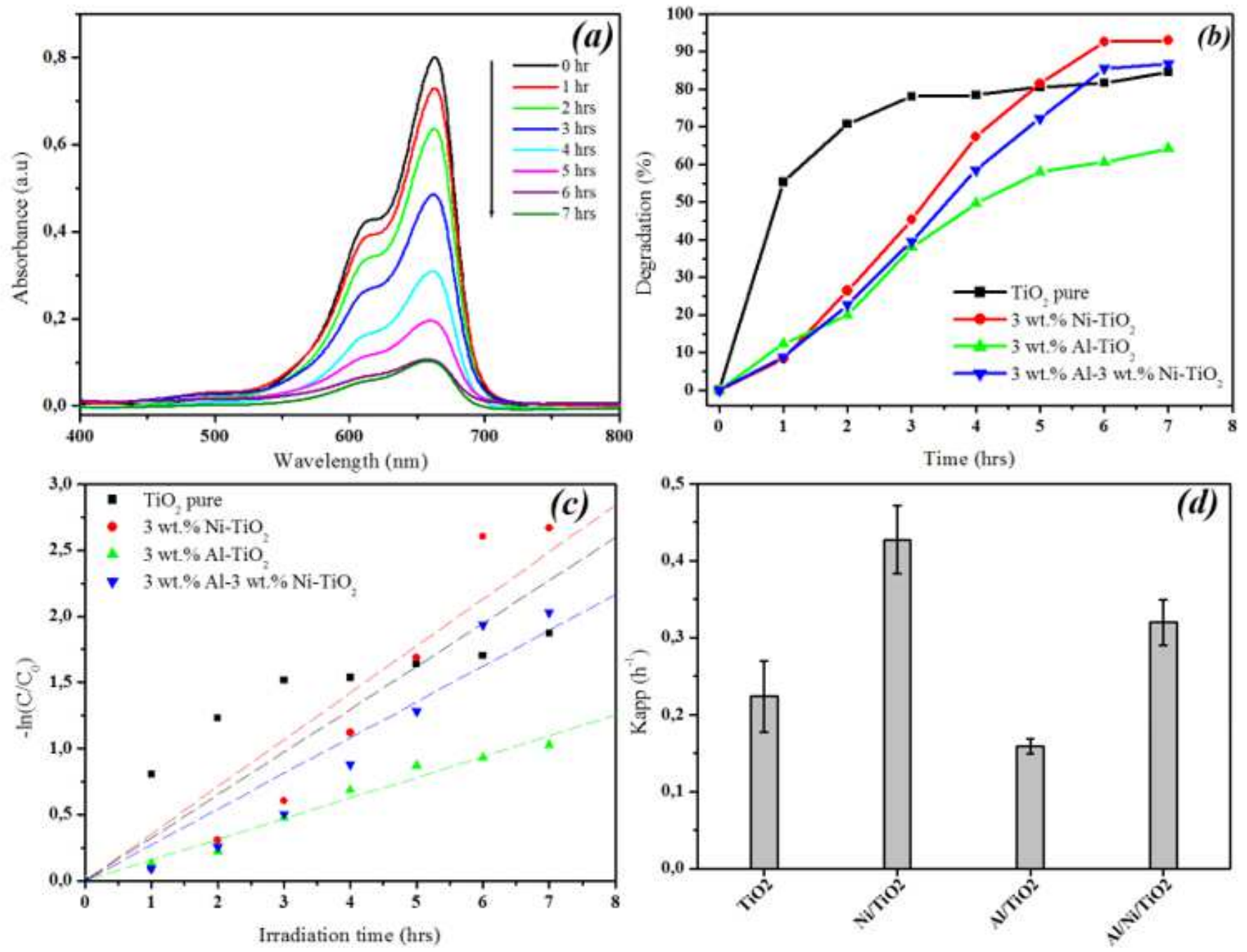

Figure 5 
(a) Variation of UV-vis spectra of MB during photodegradation over Ni/TiO2 thin films; (b) Plot of photocatalytic efficiency versus the degradation time; (c) plot of In (C/CO) versus irradiation time for TiO2 based films; (d) rate constant $\mathrm{k}$ of MB photodegradation.
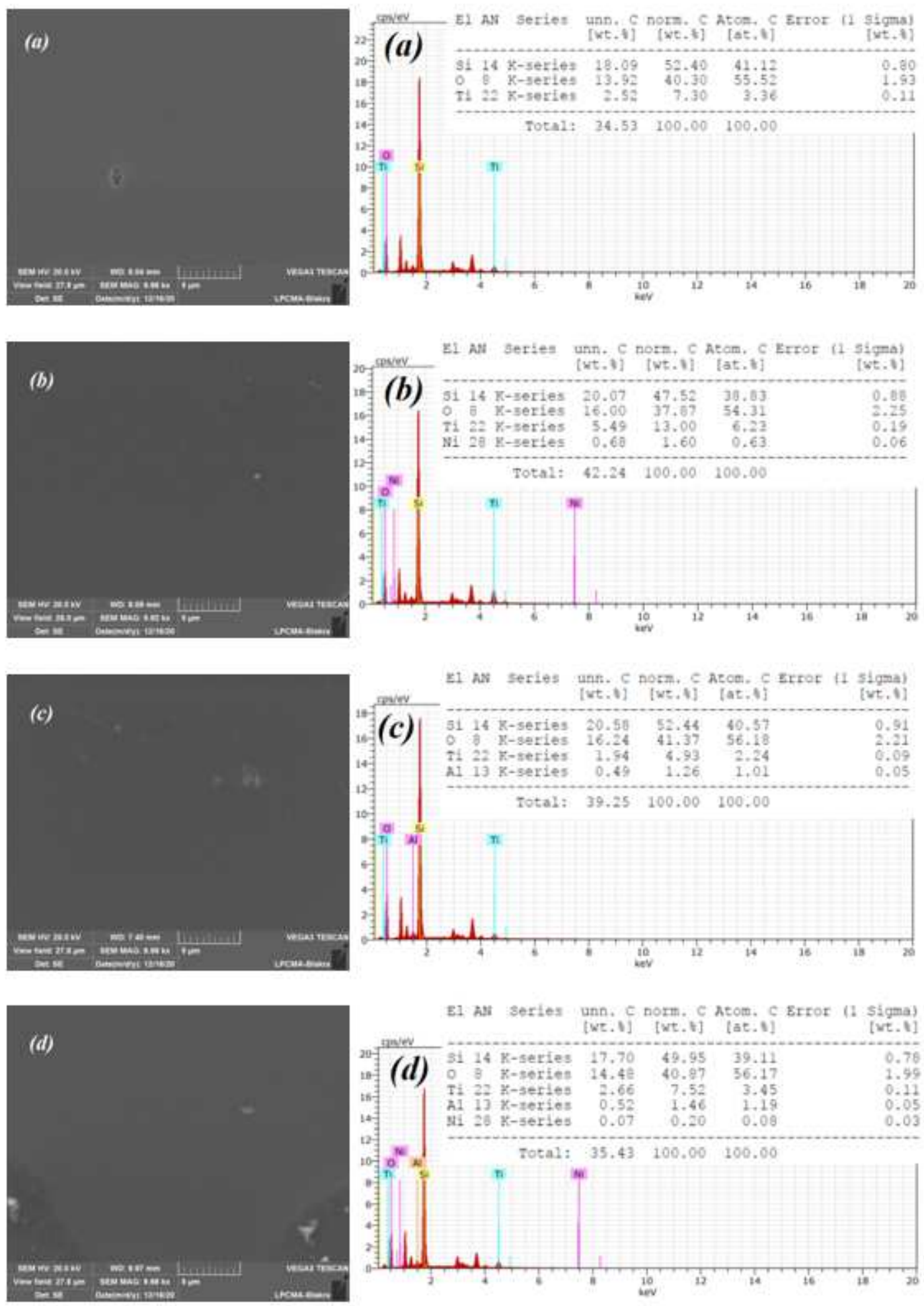

Figure 6

SEM and EDX analyses of TiO2 based thin films after photodegradation process: (a) TiO2 pure, (b) 3 wt. \%Ni-TiO2, (c) 3 wt. \%Al-TiO2, (d) 3 wt. \% Al-3 wt. \% Ni-TiO2. 


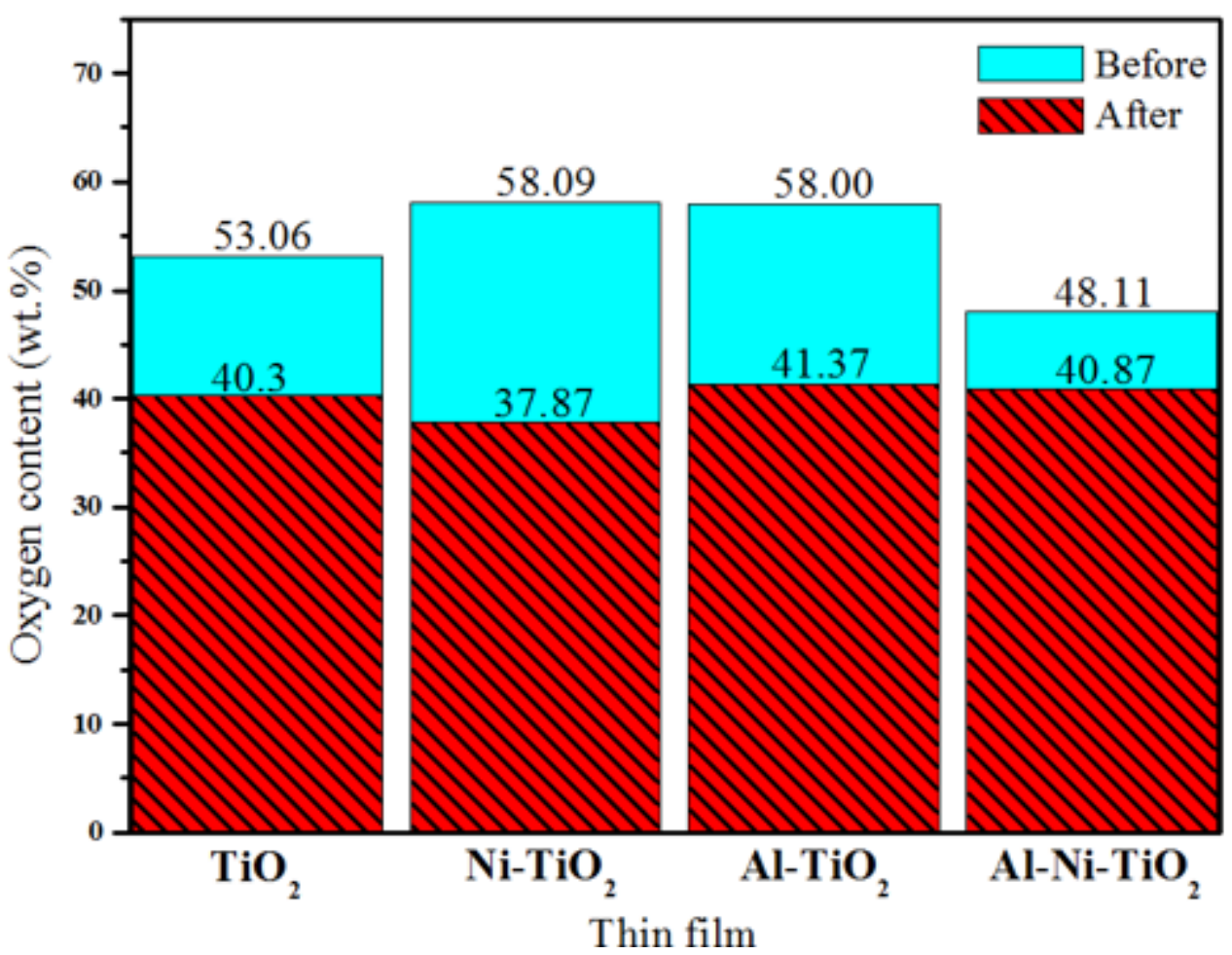

Figure 7

Effect of photocatalysis process on oxygen content in the films.
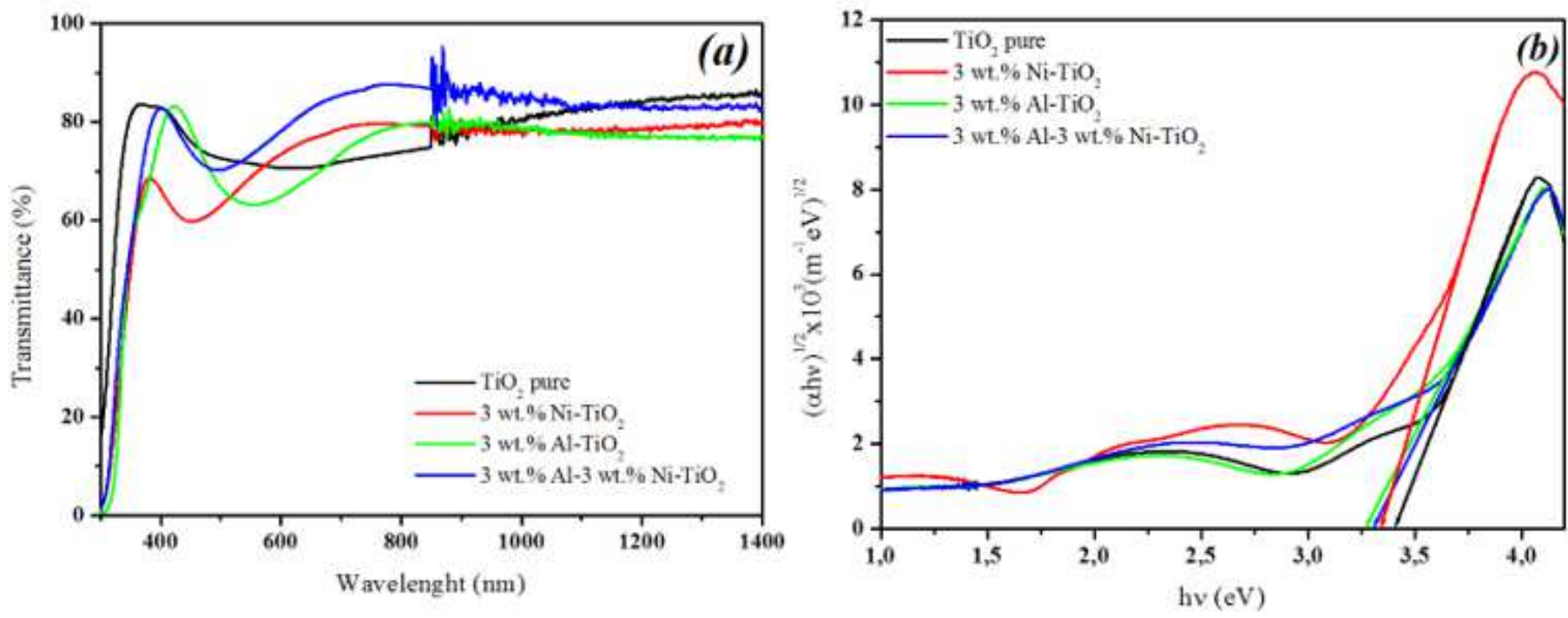

Figure 8

(a) UV-VIS optical transmission spectra of TiO2 based thin films after photodegradation process, (b) Tauc plot for the optical band gap.

\section{Supplementary Files}


This is a list of supplementary files associated with this preprint. Click to download.

- Anatase.tif 